\title{
Association of dopamine DI receptor gene polymorphism with schizophrenia: a meta-analysis
}

This article was published in the following Dove Press journal:

Neuropsychiatric Disease and Treatment

20 June 2014

Number of times this article has been viewed

Yuqing Pan

Jun Yao

Baojie Wang

Institute of Forensic Medicine, China

Medical University, Shenyang,

People's Republic of China
Correspondence: Baojie Wang Institute of Forensic Medicine, China Medical University, No 92 North Second Road, Heping District, Shenyang, I I 000 I, People's Republic of China Email wangbj77@I63.com

\begin{abstract}
To date, the role of dopamine D1 receptor ( $D R D 1)$ polymorphism in schizophrenia remains controversial. We carried out a meta-analysis to determine whether $D R D 1$ polymorphism influences the risk of schizophrenia. We examined whether rs4532 and rs5326 genetic variants are related to the etiology of schizophrenia, using a meta-analysis. Relevant case-control studies were retrieved by database searching and selected according to established inclusion criteria. A total of ten studies were identified and included in our meta-analysis, nine for rs4532, with 1,941 cases and 2,480 controls, and four for rs5326, with 1,285 cases and 1,195 controls. No significant association was found between the rs4532 locus and schizophrenia. For the rs5326 locus, the guanine-adenine (GA) genotype was associated with schizophrenia as a risk factor (for GA vs guanine-guanine [GG], odds ratio $[\mathrm{OR}]=1.36,95 \%$ confidence interval $[\mathrm{CI}]: 1.15-1.61$, $P<0.001)$. The GA genotype of rs5326 increased the risk of schizophrenia, but there was no association between rs4532 and schizophrenia. These data may provide references for casecontrol studies in schizophrenia in future.
\end{abstract}

Keywords: susceptibility, SNP, genetics, psychiatry

\section{Introduction}

Schizophrenia is a common mental disorder affected by the interaction of multiple genetic and environmental factors, with a median incidence of 15.2/100,000 persons worldwide. ${ }^{1}$ Evidence from family, adoption, and twins studies supports that its heritability is up to $80 \% .^{2}$ Many efforts have been made over the years, in order to clarify the pathological mechanisms, but a consistent conclusion hasn't been achieved given that nongenetic factors, such as social and psychological factors, have an impact on the occurrence of schizophrenia and increase the difficulty of the identification of susceptible genes. ${ }^{2}$ Nevertheless, genome-wide association studies have identified a genetic association by comparing common single nucleotide polymorphisms across the human genome ${ }^{3}$ and a number of copy number variants have been suggested as susceptibility factors for schizophrenia. ${ }^{4}$ To date, dysregulation of dopaminergic neurotransmission has been implicated in the pathogenesis of schizophrenia, ${ }^{5,6}$ and the reduction of prefrontal cortical dopamine neurotransmission likely leads to schizophrenia. ${ }^{7}$

Dopamine D1 receptor (DRD1) gene polymorphisms roughly play a role in the occurrence of schizophrenia by affecting the expression of the D1 receptor. Linkage association between $D R D 1$ and schizophrenia has been reported in Chinese, ${ }^{8}$ American, ${ }^{9}$ and Portuguese populations. ${ }^{10}$ Increasing evidence indicates that the polymorphism in the $5^{\prime}$ untranslated region of $D R D 1$ is associated with the mediation of the therapeutic response to antipsychotics, ${ }^{11}$ Moreover, present studies ${ }^{12-14}$ show that deficits in the DRD1 transmission are associated with the cognitive and negative symptoms of schizophrenia and that there is a significant decrease in $D R D 1$ expression in the basal ganglia of schizophrenic patients. ${ }^{15}$ In contrast, some studies have reported that there was no genetic association 
between the $D R D 1$ gene and the risk of schizophrenia. ${ }^{16-18}$ Therefore, the role of the DRDI gene in schizophrenia remains controversial, and a consistent conclusion has yet to be achieved. The human DRD1 gene rs4532 (A-48G) and rs5326 (G-94A) loci are two commonly studied polymorphisms that are located on the $5^{\prime}$ UTR region. The Rs4532 locus has been associated with therapeutic response to antipsychotics, ${ }^{19}$ psychotic symptoms, and prefrontal cortex-related cognitive performance. ${ }^{7,20}$ As for the rs5326 locus, this may act as a short-open-reading frame preceding the receptor cistron and encode a small peptide that inhibits receptor translation. ${ }^{21}$ Thus, it is necessary and sufficient to estimate the role of rs4532 and rs5326 loci in the pathogenesis of schizophrenia.

There are several possible explanations for this conflicting evidence, such as small sample size, ethnic differences, and publication bias. To systematically synthesize these scattered studies, a potentially useful method is to use meta-analytic techniques, which can combine the results of several studies to generate a single estimate of the major effect with enhanced precision. ${ }^{22}$ Results from multiple studies are incorporated in an unbiased fashion. ${ }^{22}$ Meta-analysis is becoming important in psychiatric genetics because of its great improvement and rapid increase of the number and size of data sets. Consequently, in our present study, we carried out a meta-analysis of studies examining the association between $D R D 1$ gene polymorphism and the risk of schizophrenia.

\section{Methods}

\section{Identification and eligibility of relevant studies}

To identify studies eligible for our meta-analysis, three online electronic databases (PubMed, Web of Science, and China National Knowledge Infrastructure [CNKI]) were searched (the last search update was December 2013). The following key words were used in the literature search: $D R D 1$, dopamine receptor 1, dopamine D1 receptor, dopamine receptor D1, schizophrenia, polymorphism, and variation. The reference lists from identified articles and potentially relevant review articles were also screened to identify additional relevant studies. Studies included in this meta-analysis met the following inclusion criteria: (1) used a case-control design; (2) included patients with schizophrenia and healthy controls; (3) offered available allele or genotype frequencies; (4) the most recent of studies with the same or overlapping data published by the same authors; and (5) published in an English language, peer-reviewed journal. Major reasons for exclusion of studies were: (1) no control population; (2) duplicate of earlier publication; and (3) no usable genotype frequency data.

\section{Data extraction}

According to the inclusion criteria listed above, two of the authors extracted information from all eligible publications independently. If there were missing data, we contacted the responsible authors to retrieve additional data not contained in the original paper. Any disagreement was resolved through discussion until the two authors reached a consensus. The following data were included from each study: the first author's last name, publication year, region, race, study design, source of controls, diagnostic criteria, detection method, and numbers of genotypes between cases and controls.

\section{Statistical analysis}

The strength of the association between two loci and schizophrenia was measured by odd ratios (OR), with $95 \%$ confidence intervals (CI). Pooled effect sizes across studies were performed by a random effects model, which evaluates the likely effect size across different populations and takes heterogeneity across studies into account. The random effects model is different from a fixed effects model, which evaluates the most likely effect size from multiple studies, hypothesizing that they are sampled from a single population, but it can be biased by high heterogeneity across studies. ${ }^{22}$

The degree of heterogeneity between studies was performed using a $Q$-statistic. ${ }^{23,24}$ A $P$-value $>0.05$ for the $Q$-test indicated a lack of heterogeneity, and $P$-value $<0.05$ indicated an existence of heterogeneity. The $I^{2}$ is the proportion of observed variance in effect sizes attributable to the true differences among studies. A conventional interpretation of $I^{2}$ is that it defines bounds for low $(<25 \%)$, moderate $(\sim 50 \%)$, and high $(>75 \%)$ heterogeneity. ${ }^{24,25}$ Subgroup analysis was performed by type of region.

An estimate of publication bias was performed by visual inspection of a funnel plot, in which the standard error of $\log (\mathrm{OR})$ of each study was plotted against its $\log (\mathrm{OR})$. An asymmetric plot indicated a possible publication bias, and the degree of asymmetry was tested using Egger's test $(P<0.05$ was considered to indicate significant publication bias). ${ }^{26}$

Sensitivity analysis was carried out to assess the potential influences of any single study on the pooled effect size. This was performed by sequentially omitting each study within each meta-analysis, in order to check for significant alterations to the pooled effect sizes. All statistical tests were two-sided. The meta-analysis was performed using Stata version 10.0 (StataCorp LP, College Station, TX, USA).

\section{Results}

The search strategy retrieved 44 potentially relevant studies. According to the inclusion criteria, ten articles were identified 
Table I Baseline characteristics of the studies included in meta-analysis

\begin{tabular}{|c|c|c|c|c|c|c|c|}
\hline Author & Year & Region & Race & Study design & Source of controls & Diagnostic criteria & Detection method \\
\hline Cichon et $\mathrm{al}^{27}$ & 1994 & German & Caucasian & Case-control & Population-based & DSM-III-R & PCR-RFLP \\
\hline Dmitrzak et al ${ }^{28}$ & 2006 & Poland & Caucasian & Case-control & Population-based & DSM-IV/ICD-I0 & PCR-RFLP \\
\hline Dollfus et $\mathrm{al}^{16}$ & 1996 & France & Caucasian & Case-control & Population-based & DSM-III-R & PCR-RFLP \\
\hline Du et $\mathrm{al}^{34}$ & 2011 & $\begin{array}{l}\text { People's Republic } \\
\text { of China }\end{array}$ & Mongolian & Case-control & Population-based & DSM-IV & Taqman $^{\circledR *}$ \\
\hline Hu et $\mathrm{al}^{29}$ & 2005 & $\begin{array}{l}\text { People's Republic } \\
\text { of China }\end{array}$ & Mongolian & Case-control & Population-based & CCMD-III & PCR-RFLP \\
\hline Iwata et $\mathrm{a}^{30}$ & 2003 & Japan & Mongolian & Case-control & Population-based & DSM-IV & PCR-RFLP \\
\hline Kojima et $\mathrm{al}^{3 !}$ & 1999 & Japan & Mongolian & Case-control & Hospital-based & DSM-IV & PCR-RFLP \\
\hline Zhang et al ${ }^{17}$ & 2010 & $\begin{array}{l}\text { People's Republic } \\
\text { of China }\end{array}$ & Mongolian & Case-control & Hospital-based & DSM-IV & Taqman $^{\circledR *}$ \\
\hline Zhu et $\mathrm{al}^{33}$ & 2011 & $\begin{array}{l}\text { People's Republic } \\
\text { of China }\end{array}$ & Mongolian & Case-control & Hospital-based & DSM-IV & MALDI-TOF \\
\hline Zhang et $\mathrm{al}^{32}$ & 2010 & $\begin{array}{l}\text { People's Republic } \\
\text { of China }\end{array}$ & Mongolian & Case-control & Hospital-based & DSM-IV & Taqman $^{\circledast *}$ \\
\hline
\end{tabular}

Note: *Taqman SNP genotyping assay.

Abbreviations: CCMD, Chinese Classification and Diagnostic Criteria of Mental Disorders; DSM, American Diagnostic and Statistical Manual of Mental Disorders; ICD, International Classification of Disease; MALDI-TOF, matrix-assisted laser desorption/lionization time of flight mass spectrometry; PCR, polymerase chain reaction; RFLP, restriction fragment length polymorphism; SNP, single nucleotide polymorphism.

and included in our meta-analysis (Table 1). Among the ten eligible studies, nine studies, ${ }^{16,17,27-33}$ with 1,941 cases and 2,480 controls, were included in the meta-analysis for the rs4532 locus and four studies, ${ }^{17,32-34}$ with 1,285 cases and 1,195 controls, in the analysis for rs5326 locus in Table 2.

\section{Meta-analysis result}

Table 3 lists the main results of pooled OR for the loci of rs4532 and rs5326 and schizophrenia. No significant association was found between the rs4532 locus and schizophrenia (for adenine-guanine $[\mathrm{AG}]$ vs adenine-adenine [AA] [OR $=0.76,95 \% \mathrm{CI}: 0.54-1.07, P=0.115]$ or guanine-guanine [GG] vs AA $[\mathrm{OR}=0.90,95 \% \mathrm{CI}: 0.64-1.26, P=0.526])$. For the rs4532 locus in the allele contrast model (guanine [G] vs adenine $[\mathrm{A}]), \mathrm{OR}=0.95,95 \% \mathrm{CI}: 0.76-1.20, P=0.665$.

For the rs5326 locus, the GA genotype was associated with schizophrenia, as a risk factor (for GA vs GG, OR =1.36, 95\% CI: 1.15-1.61, $P<0.001$ ), while no association between the AA genotype and schizophrenia was observed (for AA vs $\mathrm{GG}, \mathrm{OR}=0.89,95 \% \mathrm{CI}$ : $0.51-1.54, P=0.675)$. For rs5326 locus in the allele contrast model (A vs $\mathrm{G}$ ), $\mathrm{OR}=1.24,95 \%$ CI: $1.16-1.32, P<0.001$. The A allele was associated with schizophrenia as a risk factor. The forest plot is shown in Figure 1.

\section{Subgroup analysis}

Examination of heterogeneity among the rs4532 locus group across studies was significant. However, the genotype frequency of rs4532 locus had diverse distribution among different races. We carried out the subgroup analysis, by race, in the rs4532 locus group. Races were divided into a Mongolian subgroup (including Chinese and Japanese) and

Table 2 Genotype frequencies of rs4532 and rs5326 of all studies included in the meta-analysis

\begin{tabular}{|c|c|c|c|c|c|c|c|c|c|c|c|}
\hline \multirow[t]{2}{*}{ First author } & \multirow[t]{2}{*}{ Year } & \multicolumn{3}{|c|}{ rs4532 (case/control) } & \multicolumn{2}{|c|}{$\begin{array}{l}\text { HWE test } \\
\text { in control }\end{array}$} & \multicolumn{3}{|c|}{ rs5326 (case/control) } & \multicolumn{2}{|c|}{$\begin{array}{l}\text { HWE test } \\
\text { in control }\end{array}$} \\
\hline & & AA & AG & GG & $\chi^{2}$ & $P$-value & GG & GA & AA & $\chi^{2}$ & $P$-value \\
\hline Cichon et $\mathrm{al}^{27}$ & 1994 & $4 / 5$ & $16 / 20$ & $16 / 20$ & 0 & 1.000 & & & & & \\
\hline Dmitrzak et $\mathrm{al}^{28}$ & 2006 & $64 / 51$ & $186 / 489$ & $157 / 159$ & $13 \mid .272$ & $<0.001$ & & & & & \\
\hline Dollfus et $\mathrm{al}^{16}$ & 1996 & $1 / 4$ & $14 / 40$ & $47 / 117$ & 0.069 & 0.793 & & & & & \\
\hline Du et $\mathrm{al}^{34}$ & 2011 & & & & & & $85 / 58$ & $72 / 32$ & $5 / 11$ & 3.692 & 0.055 \\
\hline Hu et $\mathrm{al}^{29}$ & 2005 & $90 / 134$ & $21 / 52$ & $6 / 2$ & 1.559 & 0.212 & & & & & \\
\hline Iwata et $\mathrm{al}^{30}$ & 2003 & $39 / 126$ & $8 / 18$ & $\mathrm{I} / \mathrm{I}$ & 0.161 & 0.688 & & & & & \\
\hline Kojima et $\mathrm{al}^{31}$ & 1999 & $114 / 126$ & $33 / 22$ & $\mathrm{I} / 0$ & 0.954 & 0.329 & & & & & \\
\hline Zhang et al ${ }^{17}$ & 2010 & $280 / 265$ & $88 / 108$ & $5 / 6$ & 1.819 & 0.177 & $209 / 231$ & I44/I24 & $20 / 24$ & 1.725 & 0.189 \\
\hline Zhu et $\mathrm{al}^{33}$ & 2011 & $299 / 252$ & $81 / 92$ & $5 / 6$ & 0.532 & 0.466 & $204 / 216$ & $150 / 114$ & $31 / 20$ & 0.909 & $0.34 I$ \\
\hline Zhang et a ${ }^{32}$ & 2010 & $275 / 256$ & $85 / 103$ & $5 / 6$ & 1.455 & 0.228 & $18 / 24$ & $14|/| 15$ & $206 / 226$ & 3.066 & 0.080 \\
\hline
\end{tabular}

Note: All $P<0.05$ were considered to be statistically significant.

Abbreviations: A, adenine; G, guanine; HWE, Hardy-Weinberg equilibrium. 
Table 3 Main results of pooled ORs for rs4532 and rs5326

\begin{tabular}{lllllll}
\hline Genotype & OR & $\mathbf{9 5 \%} \mathbf{C l}$ & $\boldsymbol{P}$-value & $\mathbf{P}^{\mathbf{a}}$ & $\mathbf{P h}^{\mathbf{b}}$ & Combination method \\
\hline rs4532 A/G & & & & & & Random effect model \\
AG vs AA & 0.76 & $0.54-1.07$ & 0.115 & $71.9 \%$ & $<0.001$ & Random effect model \\
GG vs AA & 0.90 & $0.64-1.26$ & 0.526 & $0.0 \%$ & 0.633 & Random effect model \\
AG+GG vs AA & 0.81 & $0.62-1.05$ & 0.113 & $57.8 \%$ & 0.015 & Random effect model \\
rs5326 G/A & & & & & & Random effect model \\
GA vs GG & 1.36 & $1.15-1.61$ & $<0.001$ & $0.0 \%$ & 0.947 & Random effect model \\
AA vs GG & 0.89 & $0.51-1.54$ & 0.675 & $59.2 \%$ & 0.061 & Random effect model \\
GA+AA vs GG & 1.29 & $1.10-1.52$ & 0.002 & $0.0 \%$ & 0.8879 & Random effect model \\
\hline
\end{tabular}

Notes: ${ }^{a}{ }^{2}$ represents the variation in OR attributable to heterogeneity. ${ }^{b} P$-value of $Q$-test for the heterogeneity test.

Abbreviations: $\mathrm{Cl}$, confidence interval; OR, odds ratio; $\mathrm{A}$, adenine; $\mathrm{G}$, guanine; h, heterogeneity.

Caucasian subgroup (including German, Polish, and French). Table 4 lists the results of the subgroup analysis. No significant association was found between the rs4532 locus and schizophrenia in the Mongolian and Caucasian subgroups. Examination of heterogeneity across studies was also not significant, which showed that the heterogeneity among the rs4532 locus group was generated by different races.

\section{Sensitivity analysis}

A sensitivity analysis was carried out for each meta-analysis to assess the influence of every single study. There were no significant differences in the corresponding pooled ORs when removing one study at the time from each meta-analysis, indicating that our results were stable and reliable.

\section{Publication bias}

A funnel plot was performed to assess publication bias of the literature. The funnel plot is shown in Figure 2. Egger's test was used to supply the statistical evidence for funnel plot symmetry. For rs4532 locus, the results did not show any evidence of publication bias (for AG vs AA $[t=0.82$, $P=0.439]$ or for $\mathrm{GG}$ vs AA $[t=2.35, P=0.051])$. For the rs5326

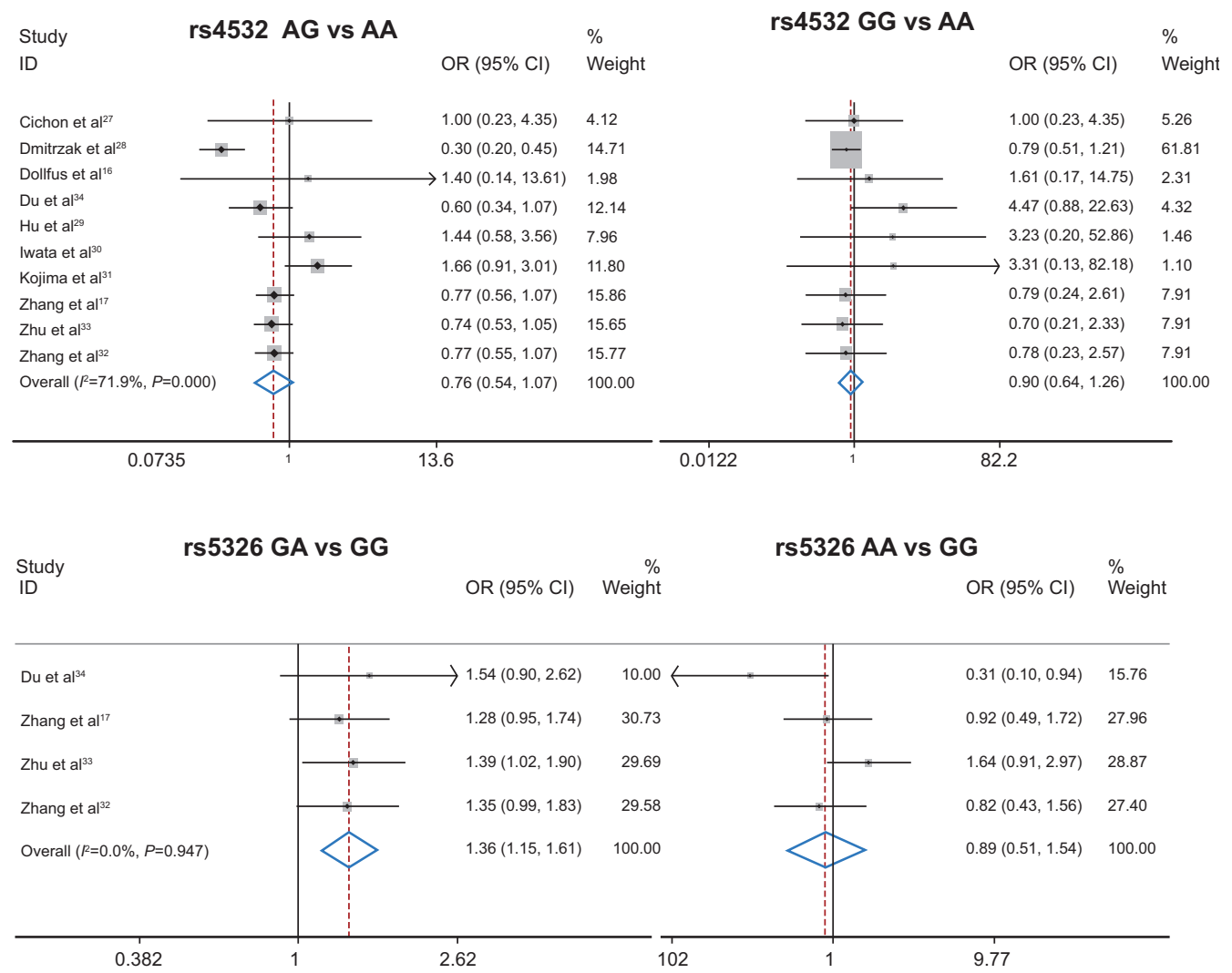

Figure I Forest plot for association between rs4532 and rs5326 loci and schizophrenia.

Note: Weights are from random effects analysis.

Abbreviations: $\mathrm{Cl}$, confidence interval; $\mathrm{OR}$, odds ratio; $\mathrm{A}$, adenine; $\mathrm{G}$, guanine. 
Table 4 Subgroup analysis between rs4532 and the risk of schizophrenia

\begin{tabular}{|c|c|c|c|c|c|}
\hline \multirow[t]{2}{*}{ Race } & \multicolumn{3}{|c|}{ Summary of pooled ORs } & \multicolumn{2}{|c|}{ Heterogeneity test } \\
\hline & OR & $95 \% \mathrm{Cl}$ & $P$-value & $p^{2 a}$ & $\mathbf{P h}^{\mathrm{b}}$ \\
\hline \multicolumn{6}{|l|}{ Mongolian } \\
\hline$A G$ vs $A A$ & 0.84 & $0.66-1.07$ & 0.157 & $41.5 \%$ & 0.128 \\
\hline GG vs $A A$ & 1.10 & $0.60-2.04$ & $0.76 \mathrm{I}$ & $1.3 \%$ & 0.408 \\
\hline$A G+G G$ vs $A A$ & 0.87 & $0.69-1.10$ & 0.236 & $41.9 \%$ & 0.126 \\
\hline \multicolumn{6}{|l|}{ Caucasian } \\
\hline$A G$ vs $A A$ & 0.52 & $0.19-1.42$ & 0.205 & $48.4 \%$ & 0.144 \\
\hline GG vs $A A$ & 0.82 & $0.55-1.23$ & 0.338 & $0.0 \%$ & 0.795 \\
\hline$A G+G G$ vs $A A$ & 0.55 & $0.29-1.04$ & 0.066 & $21.4 \%$ & 0.280 \\
\hline
\end{tabular}

Notes: ap represents the variation in OR attributable to heterogeneity. ${ }^{b} P$-value of $Q$-test for the heterogeneity test.

Abbreviations: $\mathrm{Cl}$, confidence interval; OR, odds ratio; $\mathrm{A}$, adenine; $\mathrm{G}$, guanine; h, heterogeneity.

locus, the results did not show any evidence of publication bias (for GA vs GG $[t=1.94, P=0.192]$ of for GA vs GG $[t=-2.31, P=0.147])$.

\section{Discussion}

This was a meta-analysis testing the association between the genetic polymorphisms of the $D R D 1$ gene loci of rs 4532 and rs5326 and the risk of schizophrenia. In our study, the GA genotype of the rs 5326 locus increased the risk of schizophrenia, and the A allele was also associated with schizophrenia
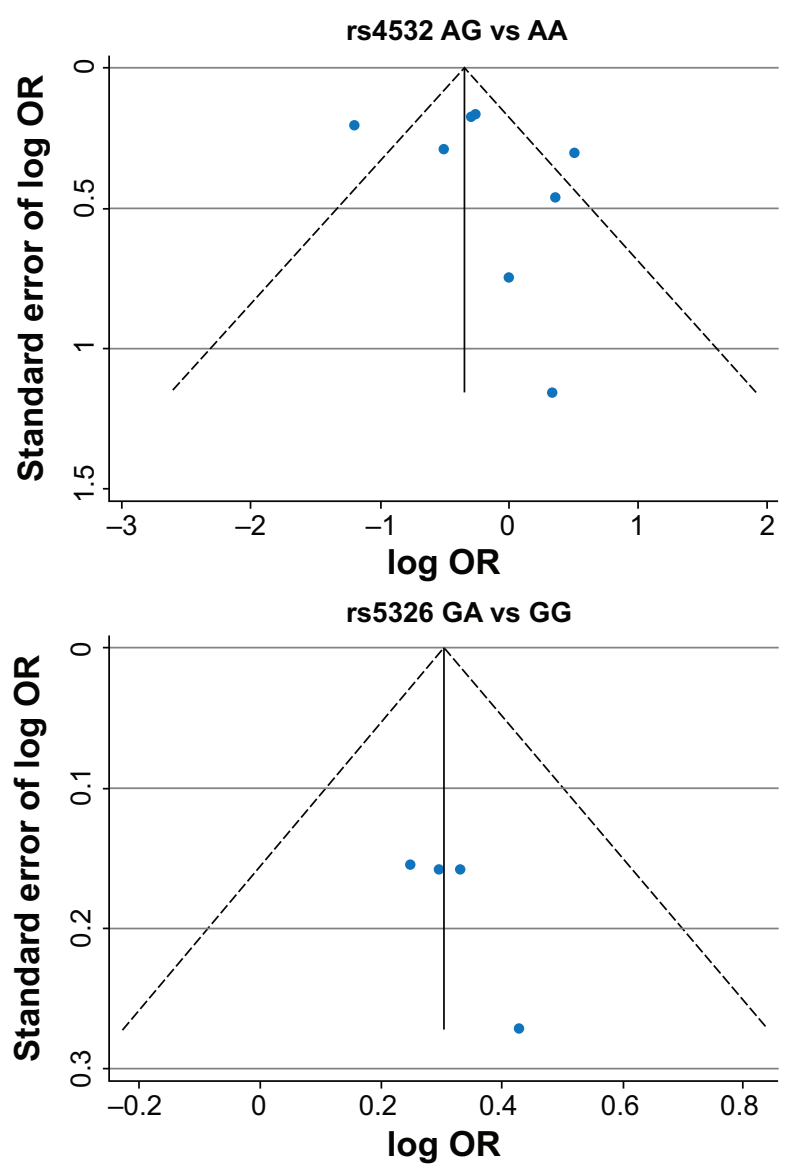

Figure 2 Funnel plot for evaluating the publication bias in schizophrenia Abbreviations: A, adenine; G, guanine; OR, odds ratio. as a risk factor, while no association was observed between rs4532 locus and schizophrenia.

Dopamine receptors play a pivotal role in regulating emotion, cognition, and motor behavior, as well as in neuroendocrine signaling. Prefrontal dopamine D1 receptor signaling is required for temporal control and for guiding intentional movements. ${ }^{35}$ Abnormal modulation of dopamine receptor signaling and disorder of dopaminergic nerve function may cause a series of neuropsychiatric defects. ${ }^{36}$ The $D R D 1$ gene has been considered a potential susceptibility gene for various
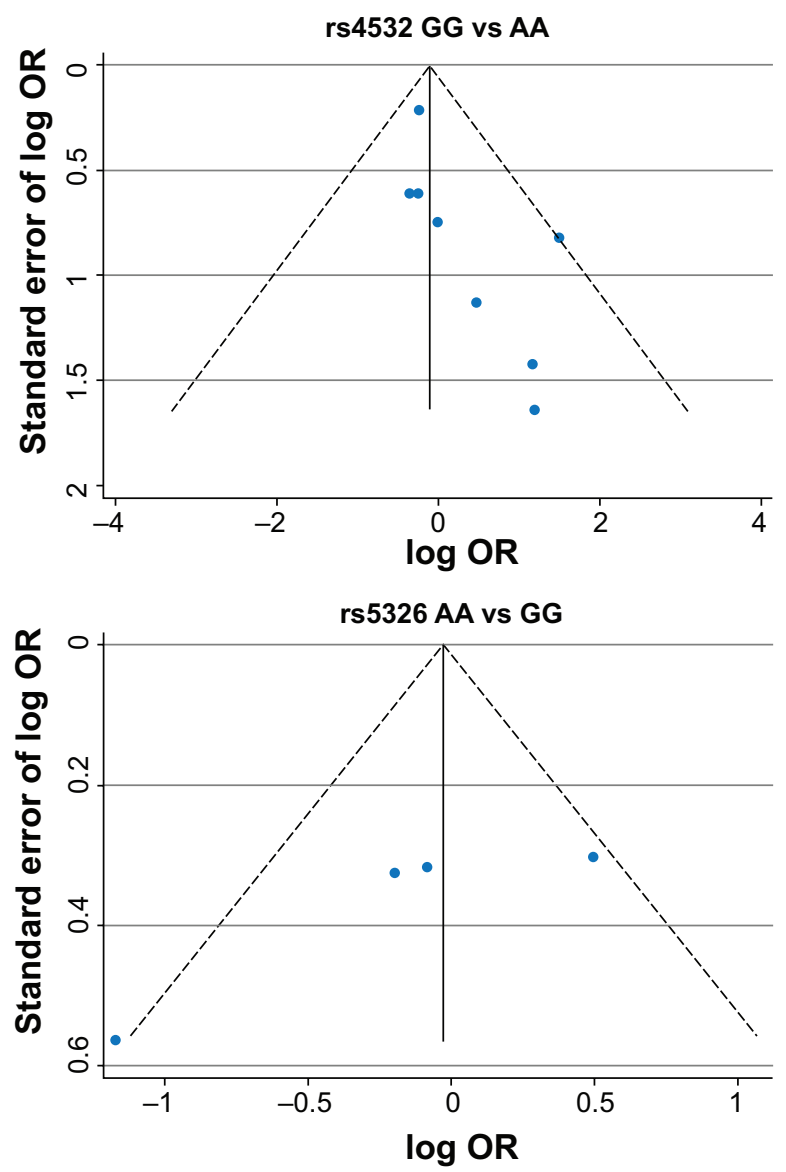
neuropsychiatric illnesses. ${ }^{9,37,38}$ Furthermore, several previous studies have reported that the DRDI gene was associated with alcohol dependence, ${ }^{39}$ hyperactivity disorders, ${ }^{40}$ nicotine addiction, ${ }^{41,42}$ and other behavioral disorders.

The DRD1 gene rs4532 and rs5326 loci are located in the $5^{\prime}$ untranslated region, where the nucleotide sequence is involved in transcription but is not being translated into amino acids. A previous meta-analysis ${ }^{43}$ indicated that the $D R D 1$ gene might contain a genuine susceptibility allele, for which the OR for rs4532 reached 1.18 (95\% CI: 1.01-1.38). Furthermore, rs4532 was associated with antipsychotic treatment in schizophrenia, ${ }^{11,19}$ and also to working memory and cognitive behavior related to the prefrontal cortex. ${ }^{20}$ These results suggest that rs4532 likely has a potential link with the etiology of schizophrenia. Rs4532, due to a G to A substitution, may act as a short open reading frame preceding the receptor cistron and encode a small peptide that inhibits receptor translation. ${ }^{21}$ However, the positive or negative association between the rs5326 locus and schizophrenia hasn't been determined. ${ }^{32,34}$

Heterogeneity is usually a concern in a meta-analysis. In our study, evidence of heterogeneity was observed in the rs4532 group. This might have been partially due to different races because the genotype frequencies changed greatly in different regions. When subgroup analysis was carried out to explain the heterogeneity, we found that differences in races could lead to the heterogeneity among the studies. The funnel plot was not completely symmetrical, which indicated the potential presence of publication bias. This could have resulted from the following causes: firstly, negative results were less often published compared with positive results, which made it hard for us to collect them for analysis; second, the literature collection wasn't comprehensive, and the number of published studies in our meta-analysis wasn't sufficiently large; and third, studies written in other languages were difficult to collect and analyze.

Several limitations in our study should be noted. First, the sample sizes of several studies included were fairly small and lacked a strong statistical power. Furthermore, the factors of $\operatorname{sex}^{38}$ and age may affect the incidence of the disease. In addition, we didn't consider the role of different environments, and it is possible that environment may also influence the risk of schizophrenia. Further, epigenetic mechanisms altering the chromatin structure, such as histone acetylation and deoxyribonucleic acid methylation, may mediate effects of environmental factors in transcriptional regulation of specific genes and may be a prominent factor in gene-environmental interaction. ${ }^{44}$ Thus, further studies are needed to investigate the effect of genetic susceptibility and environment in different ethnicities and between males and females, to fully attest to our results. In the future, research into the role of $D R D 1$ gene polymorphisms in schizophrenia endophenotypes could be useful.

In conclusion, our meta-analysis demonstrated that the A allele of the $D R D 1$ rs5326 polymorphism might be a potential risk factor in schizophrenia. As the number of eligible studies was limited in this meta-analysis, these results need further investigation.

\section{Acknowledgment}

Special thanks to Hao Pang for critically reviewing the manuscript for important intellectual content.

\section{Author contributions}

Yuqing Pan participated in the design of the study and performed the statistical analysis. Jun Yao carried out the studies and drafted the manuscript. Baojie Wang conceived the study and participated in its design and coordination. All authors contributed toward the drafting and revising of the final manuscript.

\section{Disclosure}

The authors report no conflicts of interest in this work.

\section{References}

1. McGrath J, Saha S, Chant D, Welham J. Schizophrenia: a concise overview of incidence, prevalence, and mortality. Epidemiol Rev. 2008;30: 67-76.

2. Sullivan PF, Kendler KS, Neale MC. Schizophrenia as a complex trait: evidence from a meta-analysis of twin studies. Arch Gen Psychiatry. 2003;60(12):1187-1192.

3. Schierding W, Cutfield WS, O'Sullivan JM. The missing story behind Genome Wide Association Studies: single nucleotide polymorphisms in gene deserts have a story to tell. Front Genet. 2014;5:39.

4. Rees E, Walters JT, Georgieva L, et al. Analysis of copy number variations at 15 schizophrenia-associated loci. Br J Psychiatry. 2014;204(2): $108-114$.

5. Howes OD, Kapur S. The dopamine hypothesis of schizophrenia: version III - the final common pathway. Schizophr Bull. 2009;35(3): $549-562$.

6. Abi-Dargham A, Meyer JM. Schizophrenia: the role of dopamine and glutamate. J Clin Psychiatry. 2014;75(3):274-275.

7. Rybakowski JK, Borkowska A, Czerski PM, Kapelski P, DmitrzakWeglarz M, Hauser J. An association study of dopamine receptors polymorphisms and the Wisconsin Card Sorting Test in schizophrenia. J Neural Transm. 2005;112(11):1575-1582.

8. Zheng Y, Wang X, Gu N, et al. A two-stage linkage analysis of Chinese schizophrenia pedigrees in 10 target chromosomes. Biochem Biophys Res Commun. 2006;342(4):1049-1057.

9. Escamilla MA, Ontiveros A, Nicolini H, et al. A genome-wide scan for schizophrenia and psychosis susceptibility loci in families of Mexican and Central American ancestry. Am J Med Genet B Neuropsychiatr Genet. 2007;144B(2):193-199.

10. Sklar P, Pato MT, Kirby A, et al. Genome-wide scan in Portuguese Island families identifies $5 \mathrm{q} 31-5 \mathrm{q} 35$ as a susceptibility locus for schizophrenia and psychosis. Mol Psychiatry. 2004;9(2):213-218. 
11. Hwang R, Shinkai T, De Luca V, et al. Association study of four dopamine D1 receptor gene polymorphisms and clozapine treatment response. J Psychopharmacol. 2007;21(7):718-727.

12. Okubo Y, Suhara T, Suzuki K, et al. Decreased prefrontal dopamine D1 receptors in schizophrenia revealed by PET. Nature. 1997; 385(6617):634-636.

13. Karlsson P, Farde L, Halldin C, Sedvall G. PET study of D(1) dopamine receptor binding in neuroleptic-naive patients with schizophrenia. Am J Psychiatry. 2002;159(5):761-767.

14. Abi-Dargham A, Mawlawi O, Lombardo I, et al. Prefrontal dopamine D1 receptors and working memory in schizophrenia. J Neurosci. 2002; 22(9):3708-3719.

15. Sedvall G, Pauli S, Karlsson P, et al. PET imaging of neuroreceptors in schizophrenia. Eur Neuropsychopharmacol. 1995;5 Suppl:S25-S30.

16. Dollfus S, Campion D, Vasse T, et al. Association study between dopamine D1, D2, D3, and D4 receptor genes and schizophrenia defined by several diagnostic systems. Biol Psychiatry. 1996;40(5):419-421.

17. Zhang C, Xie B, Du YS, et al. [Gene-gene interaction between DNMT3B and DRD1 in schizophrenia]. Zhonghua Yi Xue Za Zhi. 2010;90(43): 3059-3062. Chinese.

18. Howe AS, Leung T, Bani-Fatemi A, et al. Lack of association between dopamine- $\beta$ hydroxylase gene and a history of suicide attempt in schizophrenia: comparison of molecular and statistical haplotype analyses. Psychiatr Genet. 2014;24(3):110-115.

19. Potkin SG, Basile VS, Jin Y, et al. D1 receptor alleles predict PET metabolic correlates of clinical response to clozapine. Mol Psychiatry. 2003;8(1):109-113.

20. Williams GV, Castner SA. Under the curve: critical issues for elucidating D1 receptor function in working memory. Neuroscience. 2006 139(1):263-276.

21. Fung MM, Rana BK, Tang CM, et al. Dopamine D1 receptor (DRD1) genetic polymorphism: pleiotropic effects on heritable renal traits. Kidney Int. 2009;76(10):1070-1080

22. Munafò MR, Flint J. Meta-analysis of genetic association studies. Trends Genet. 2004;20(9):439-444.

23. Zintzaras E, Ioannidis JP. Heterogeneity testing in meta-analysis of genome searches. Genet Epidemiol. 2005;28(2):123-137.

24. Higgins JP, Thompson SG, Deeks JJ, Altman DG. Measuring inconsistency in meta-analyses. BMJ. 2003;327(7414):557-560.

25. Higgins JP, Thompson SG. Quantifying heterogeneity in a metaanalysis. Stat Med. 2002;21(11):1539-1558.

26. Egger M. Bias in meta-analysis detected by a simple, graphical test. BMJ. 1997;315(7109):629-634.

27. Cichon S, Nöthen MM, Rietschel M, Körner J, Propping P. Singlestrand conformation analysis (SSCA) of the dopamine D1 receptor gene (DRD1) reveals no significant mutation in patients with schizophrenia and manic depression. Biol Psychiatry. 1994;36(12):850-853.

28. Dmitrzak-Weglarz M, Rybakowski JK, Slopien A, et al. Dopamine receptor D1 gene $-48 \mathrm{~A} / \mathrm{G}$ polymorphism is associated with bipolar illness but not with schizophrenia in a Polish population. Neuropsychobiology. 2006;53(1):46-50.
29. Hu Y, Wang G, Wang H, Liu Z, Tang J. Distribution of dopamine D1 receptor $-48 \mathrm{~A} / \mathrm{G}$ gene polymorphism of healthy Han population in China. Chinese Journal Of Clinical Rehabilitation. 2005;9(20):152-153.

30. Iwata Y, Matsumoto H, Minabe Y, et al. Early-onset schizophrenia and dopamine-related gene polymorphism. Am J Med Genet B Neuropsychiatr Genet. 2003;116B(1):23-26.

31. Kojima H, Ohmori O, Shinkai T, Terao T, Suzuki, Abe K. Dopamine D1 receptor gene polymorphism and schizophrenia in Japan. Am J Med Genet. 1999;88(2):116-119.

32. Zhang C, Fang Y, Xie B, et al. No genetic association between dopamine D1 receptor gene and [early onset] schizophrenia. Psychiatry Res. 2010;177(3):350-353.

33. Zhu F, Yan CX, Wang Q, et al. An association study between dopamine D1 receptor gene polymorphisms and the risk of schizophrenia. Brain Res. 2011;1420:106-113.

34. Du Z, Zhang Y, Cheng Y, Zhu C. -94 G/A polymorphism in the dopamine D1 receptor gene is associated with schizophrenia in a Chinese Han population from Shandong province. Neural Regen Res. 2011; 06(19):1484-1487.

35. Narayanan NS, Land BB, Solder JE, Deisseroth K, DiLeone RJ. Prefrontal D1 dopamine signaling is required for temporal control. Proc Natl Acad Sci U S A. 2012;109(50):20726-20731.

36. Girault JA, Greengard. The neurobiology of dopamine signaling. Arch Neurol. 2004;61(5):641-644.

37. Ni X, Trakalo JM, Mundo E, et al. Linkage disequilibrium between dopamine D1 receptor gene (DRD1) and bipolar disorder. Biol Psychiatry. 2002;52(12):1144-1150.

38. Hoenicka J, Garrido E, Ponce G, et al. Sexually dimorphic interaction between the DRD1 and COMT genes in schizophrenia. Am JMed Genet B Neuropsychiatr Genet. 2010;153B(4):948-954.

39. Batel P, Houchi H, Daoust M, Ramoz N, Naassila M, Gorwood. A haplotype of the DRD1 gene is associated with alcohol dependence. Alcohol Clin Exp Res. 2008;32(4):567-572.

40. Bobb AJ, Addington AM, Sidransky E, et al. Support for association between ADHD and two candidate genes: NET1 and DRD1. Am JMed Genet B Neuropsychiatr Genet. 2005;134B(1):67-72.

41. Huang W, Ma JZ, Payne TJ, Beuten J, Dupont RT, Li MD. Significant association of DRD1 with nicotine dependence. Hum Genet. 2008; 123(2):133-140.

42. Novak G, LeBlanc M, Zai C, et al. Association of polymorphisms in the BDNF, DRD1 and DRD3 genes with tobacco smoking in schizophrenia. Ann Hum Genet. 2010;74(4):291-298.

43. Allen NC, Bagade S, McQueen MB, et al. Systematic meta-analyses and field synopsis of genetic association studies in schizophrenia: the SzGene database. Nat Genet. 2008;40(7):827-834.

44. Schmitt A, Malchow B, Hasan A, Falkai P. The impact of environmental factors in severe psychiatric disorders. Front Neurosci. 2014;8:19.
Neuropsychiatric Disease and Treatment

\section{Publish your work in this journal}

Neuropsychiatric Disease and Treatment is an international, peerreviewed journal of clinical therapeutics and pharmacology focusing on concise rapid reporting of clinical or pre-clinical studies on a range of neuropsychiatric and neurological disorders. This journa is indexed on PubMed Central, the 'PsycINFO' database and CAS,

\section{Dovepress}

and is the official journal of The International Neuropsychiatric Association (INA). The manuscript management system is completely online and includes a very quick and fair peer-review system, which is all easy to use. Visit http://www.dovepress.com/testimonials.php to read real quotes from published authors. 